\title{
Bioequivalence evaluation of two amlodipine salts, besylate and orotate, each in a fixed-dose combination with olmesartan in healthy subjects
}

This article was published in the following Dove Press journal:

Drug Design, Development and Therapy

2 June 2015

Number of times this article has been viewed

\author{
Soo-Yun Lee' \\ Jung-Ryul Kim ${ }^{2,3}$ \\ Jin Ah Jung ${ }^{4}$ \\ Wooseong Huh ${ }^{2,5}$ \\ Mi Young Bahng ${ }^{6}$ \\ Jae-Wook Ko ${ }^{1,2}$
}

'Department of Health Sciences and Technology, SAIHST, Sungkyunkwan University, Seoul, Republic of Korea; ${ }^{2}$ Department of Clinical Pharmacology and Therapeutics, Samsung Medical Center, Seoul, Republic of Korea; ${ }^{3}$ Department of Clinical Research Design and Evaluation, SAIHST, Sungkyunkwan University, Seoul, Republic of Korea; ${ }^{4}$ Department of Clinical Pharmacology, Inje University, Busan Paik Hospital, Busan, Republic of Korea; ${ }^{5}$ Department of Internal Medicine, Samsung Medical Center, Sungkyunkwan University School of Medicine, Seoul, Republic of Korea; ${ }^{6}$ Dong-A ST Co., Ltd., Seoul, Republic of Korea

\author{
Correspondence: Jae-Wook Ko \\ Department of Clinical Pharmacology \\ and Therapeutics, 9th Floor, \\ Main Building, Samsung Medical Center, \\ 8I Irwon-ro, Gangnam-gu, Seoul, \\ Republic of Korea I35-7/0 \\ $\mathrm{Tel}+82234103690$ \\ Fax +82 23410 0915 \\ Email jw070I.ko@samsung.com
}

\begin{abstract}
A fixed-dose combination of amlodipine and olmesartan is used to treat high blood pressure in patients whose hypertension is not sufficiently controlled with either drug alone. The objective of this study was to evaluate the bioequivalence of two fixed-dose combinations, ie, amlodipine orotate/olmesartan medoxomil 10/40 mg and amlodipine besylate/olmesartan medoxomil 10/40 mg, in healthy subjects. A randomized, open-label, single-dose, two-sequence, two-period, crossover study was conducted in 30 healthy adult volunteers. Blood samples were collected for up to 72 hours post-dose in each period. Safety data included the results of physical examinations, clinical laboratory tests, vital signs, an electrocardiogram, and adverse events. For both amlodipine and olmesartan, the $90 \%$ confidence intervals for the geometric mean ratios of $\mathrm{AUC}_{\text {last }}$ and time to peak plasma concentration fell within the bioequivalence acceptance criteria. The two fixed-dose combinations showed similar safety profiles. Amlodipine orotate/olmesartan medoxomil 10/40 mg was bioequivalent to amlodipine besylate/olmesartan medoxomil 10/40 mg.
\end{abstract}

Keywords: amlodipine orotate, amlodipine besylate, olmesartan medoxomil, fixed-dose combination, bioequivalence

\section{Introduction}

Amlodipine is one of the most widely used 1,4-dihydropyridine calcium channel antagonists. Amlodipine inhibits the influx of calcium ions through L-type calcium channels that are located mainly in vascular smooth muscle cells, resulting in decreased vascular smooth muscle contractility and vasodilation. ${ }^{1}$ Amlodipine is slowly but completely absorbed, with moderately high bioavailability (64\%-90\%). This drug is extensively converted to inactive metabolites via hepatic metabolism, with $10 \%$ of the parent compound and $60 \%$ of the metabolites excreted in the urine. ${ }^{2}$

Olmesartan is an angiotensin II receptor blocker that is commonly used to treat hypertension. This drug inhibits the vasoconstrictive and aldosterone-secreting effects by blocking the binding of angiotensin II to its receptors, and results in a decrease in blood pressure. ${ }^{1,3}$ With oral administration of olmesartan medoxomil, conversion to the active compound, olmesartan, occurs rapidly and completely during gastrointestinal absorption, and the drug is eliminated mainly in the urine (35\%-50\%) and feces. ${ }^{4}$

The 2013 European Society of Hypertension and European Society of Cardiology guidelines underline that regardless of which drug is employed, monotherapy effectively reduces blood pressure in only a limited number of hypertensive patients and that most patients require a combination of at least two drugs to achieve blood pressure control. ${ }^{5}$ For this reason, fixed-dose combination formulations of two or more classes 
of antihypertensive drugs have been developed, and are used in patients whose blood pressure is not sufficiently controlled when only one drug is used. Compared with separate tablets for each drug, the fixed-dose combination benefits patients by reducing manufacturing costs and by providing the synergistic effect of a potentially lower dose and convenience in terms of administration and compliance.

Combination of an angiotensin receptor blocker and a calcium channel antagonist is one of the preferred regimens, and is the most widely used two-drug combination for treating hypertension. ${ }^{5}$ Previous studies have shown no pharmacokinetic interaction between olmesartan and amlodipine, supporting coadministration of olmesartan and amlodipine in fixed-dose combination. ${ }^{6,7}$ The objective of this study was to evaluate the bioequivalence of two fixed-dose combinations, ie, amlodipine orotate/olmesartan medoxomil 10/40 mg and amlodipine besylate/olmesartan medoxomil 10/40 mg, in healthy subjects.

\section{Materials and methods Study design}

This was a randomized, open-label, single-dose, two-treatment, two-sequence, two-period, crossover study conducted at a single center (Clinical Trial Center, Samsung Medical Center, Seoul, Republic of Korea). Healthy adults aged 19-55 years without a record of congenital or chronic disease and with a body mass index of 19-27 were eligible for participation. Volunteers were ineligible if they had a history of alcohol abuse or illegal drug use, smoked more than 10 cigarettes per day, or had a history of clinically significant medical conditions. Selected subjects were randomized to receive either amlodipine besylate/olmesartan medoxomil 10/40 mg (Sevikar ${ }^{\circledR}$; Daiichi Sankyo Korea Co Ltd, Seoul, Republic of Korea) or amlodipine orotate/olmesartan medoxomil 10/40 mg (G3041'TM; Dong-A ST Co Ltd, Seoul, Republic of Korea). The washout period in this study was 2 weeks.

Subjects were admitted to our hospital and fasted overnight before administration of the study drug. They remained in the hospital for 24 hours after dosing. Venous blood samples $(8 \mathrm{~mL})$ were collected from an indwelling catheter or by venipuncture before dosing and $0.5,1,1.5,2,2.5,3$, $4,6,7,8,12,24,48$, and 72 hours after dosing. Blood was centrifuged at approximately $2,000 \times g$ for 10 minutes at $4^{\circ} \mathrm{C}$, and plasma samples were stored at $-70^{\circ} \mathrm{C}$ prior to analysis.

This study was conducted in accordance with the principles of the Declaration of Helsinki and its amendments, and was performed in compliance with Good Clinical Practice. ${ }^{8}$ Ethical approval was obtained from the institutional review board of the Samsung Medical Center, Republic of Korea (November 18, 2013) before initiation of the study. Written informed consent was obtained from all volunteers prior to their participation in the study.

\section{Analytical methods}

Concentrations of amlodipine and olmesartan in plasma were determined using ultra performance liquid chromatography coupled to tandem mass spectrometry. Chromatography was performed on an Acquity UPLC ${ }^{\text {TM }}$ system (Waters Corporation, Milford, MA, USA) using an Acquity UPLC $\mathrm{BEH} \mathrm{C}_{18}$ column $(50 \mathrm{~mm} \times 2.1 \mathrm{~mm}, 1.7 \mu \mathrm{m}$; Waters Corporation). Tandem mass spectrometric detection was carried out on a Xevo ${ }^{\mathrm{TM}} \mathrm{TQ}-\mathrm{S}$ mass spectrometer (Waters Corporation) for amlodipine and a Xevo TQ mass spectrometer (Waters Corporation) for olmesartan, with an electrospray ionization interface operated in positive ionization mode. The precision and accuracy were adequate for determination of amlodipine and olmesartan in plasma.

\section{Pharmacokinetic analysis}

Data for the concentration in plasma versus time for both olmesartan and amlodipine were analyzed with noncompartmental methods. The pharmacokinetic parameters were characterized using Phoenix ${ }^{\circledR}$ WinNonlin ${ }^{\circledR}$ (version 6.3; Pharsight, Mountain View, CA, USA) as appropriate. The highest observed concentration in plasma and the corresponding sampling time were defined as $\mathrm{C}_{\text {max }}$ and $\mathrm{t}_{\text {max }}$, respectively. The elimination rate constant $\left(\lambda_{z}\right)$ was estimated, and $t_{1 / 2}$ was defined as the apparent terminal half-life, calculated as $(\ln 2) / \lambda_{\mathrm{z}}$. The area under the concentration-time curve (AUC) was estimated using the trapezoidal rule from time 0 to the last measurable concentration $\left(\mathrm{AUC}_{\text {last }}\right)$ and with extrapolation to infinity $\left(\mathrm{AUC}_{\text {inf }}\right)$.

\section{Pharmacodynamic analysis}

Blood pressure in the upper arm was measured in a sitting position. Subjects were instructed to sit quietly while blood pressure was measured, and to rest for at least 5 minutes before beginning the blood pressure measurements. Systolic blood pressure, diastolic blood pressure, and heart rate were recorded before dosing and at 1, 2, 3, 4, 5, 6, 7, 8, 10, 12, 24, 48, and 72 hours after doing using a semi-automated cuff-oscillometric sphygmomanometer (HEM-CR23; Omron Corporation, Tokyo, Japan) with an automatic blood pressure monitor (YM1000; Mediana, Wonju, Republic of Korea). Pharmacodynamic data were summarized by means of maximum effect $\left(\mathrm{E}_{\max }\right)$, time to $\mathrm{E}_{\max }\left(\mathrm{T}_{\mathrm{Emax}}\right)$, and area under the 
effect-time curve from time 0 to 24 hours $\left(\mathrm{AUEC}_{24}\right)$ using the trapezoidal rule. The $\mathrm{E}_{\max }$ and $\mathrm{AUEC}_{24}$ were calculated for the change from baseline (average of three predose values) for each subject.

\section{Safety assessment}

Adverse events (AEs) were recorded throughout the study and coded using MedDRA ${ }^{\circledR}$ (version 16.0; Maintenance and Support Services Organization, Chantilly, VA, USA). The investigator recorded and assessed the severity of the AEs and their causal relationship to the study drug. Additional safety parameters included physical examination, an electrocardiogram, and clinical laboratory tests (hematology, blood chemistry, and urinalysis).

\section{Statistical analysis}

The pharmacokinetic and pharmacodynamic parameters were summarized with descriptive statistics (arithmetic mean and standard deviation, or median and interquartile range, as appropriate). The pharmacokinetic parameters were logtransformed and analyzed using a linear mixed model, with treatment, sequence, and period as a fixed effect and subject as a random effect model. For $\mathrm{C}_{\max }$ and $\mathrm{AUC}_{\text {last }}$, estimates and $90 \%$ confidence intervals for the ratios of the geometric means of the two study drugs (test/reference drug) were derived from the model. Given the nonparametric nature of $\mathrm{t}_{\max }$, the difference (test-reference) for $\mathrm{t}_{\text {max }}$ was assessed using the Wilcoxon signed rank test.

The safety parameters were also summarized with descriptive statistics. Qualitative variables were described by number and percentage of subjects, whereas quantitative variables were described as the arithmetic mean, standard deviation, median, and range. All statistical analyses were performed using $\mathrm{SAS}^{\circledR}$ (version 9.2; SAS Institute, Cary, NC, USA).

\section{Results \\ Subjects}

A total of 30 healthy subjects were enrolled and completed this study. They were all men, with a mean age of 28.9 (22.0-53.0) years, a mean weight of $68.9(53.3-88.0) \mathrm{kg}$, and a mean body mass index of 22.9 (19.0-26.9). The average amount of alcohol consumed before study enrollment differed between sequences $(P<0.05)$. However, this difference was not considered important because the study was carried out with a crossover design, and all data were analyzed by adjusting for sequence effect. Other baseline characteristics showed no significant differences between sequences.

\section{Pharmacokinetics}

The plasma concentration-time profiles for amlodipine and olmesartan are presented in Figure 1. The amlodipine plasma concentrations increased gradually, reached a peak at a median $\mathrm{t}_{\max }$ of 6 hours, and declined thereafter, with a mean $t_{1 / 2}$ of about 40 hours for the test drug (amlodipine orotate/olmesartan medoxomil 10/40 mg) and reference drug (amlodipine besylate/olmesartan medoxomil 10/40 mg, Figure 1A). Olmesartan plasma concentrations increased, reached a peak at a median $\mathrm{t}_{\max }$ of 2 hours, and declined thereafter, with a mean $t_{1 / 2}$ of about 11 hours (Figure 1B). The summary and statistical comparison results for the amlodipine and olmesartan pharmacokinetic parameters for the two study drugs are presented in Table 1 . The mean $\mathrm{t}_{1 / 2}$ of amlodipine was 39.9 hours for the test drug, and was comparable with that of the reference drug at 40.5 hours. The mean $t_{1 / 2}$ of olmesartan was also similar between the test drug (10.9 hours) and the reference drug (11.1 hours). The 90\% confidence intervals for the ratio of the geometric mean (test/reference drug) for amlodipine $\mathrm{C}_{\max }$ and $\mathrm{AUC}_{\text {last }}$ are presented in Table 1.

\section{Pharmacodynamics}

Mean changes in heart rate, systolic blood pressure, and diastolic blood pressure after dosing of the two study drugs are shown in Figure 2 and Table 2. Systolic and diastolic blood pressure gradually declined, reached the $\mathrm{E}_{\max }$ at approximately 8 hours, and recovered. Heart rate increased, reached the $\mathrm{E}_{\max }$ at approximately 7 hours, and recovered.

\section{Safety}

Administration of a single oral dose of either the test drug or reference drug was found to be safe in healthy subjects. The summary of AEs for the study drugs is presented in Table 3. Thirteen AEs were suspected to be related to the study drug (ten [33.3\%] subjects): five AEs for the test drug (five [16.7\%] subjects) and eight AEs for the reference drug (eight [26.7\%] subjects). All AEs were mild or moderate in severity. No severe, serious, or life-threatening AEs were reported throughout the study. We found no clinically significant changes on electrocardiography or physical examination. The majority of clinical laboratory test results were within the normal range or not clinically significant.

\section{Discussion}

In this study, the amlodipine orotate/olmesartan medoxomil $10 / 40 \mathrm{mg}$ fixed-dose combination was bioequivalent to the amlodipine besylate/olmesartan medoxomil 10/40 mg fixed-dose combination. Amlodipine exposure was slightly 
A

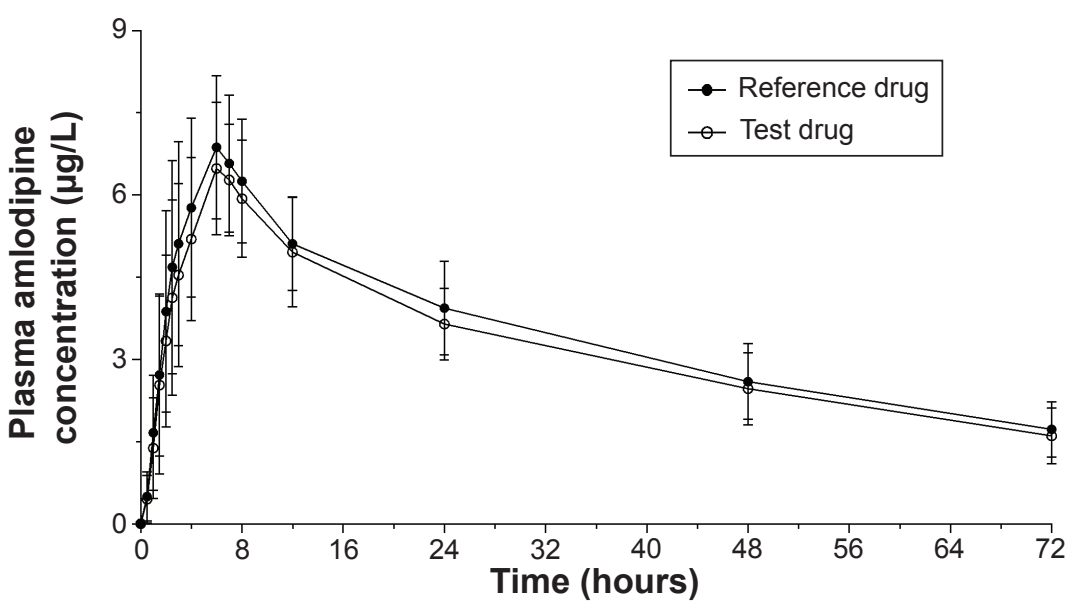

B

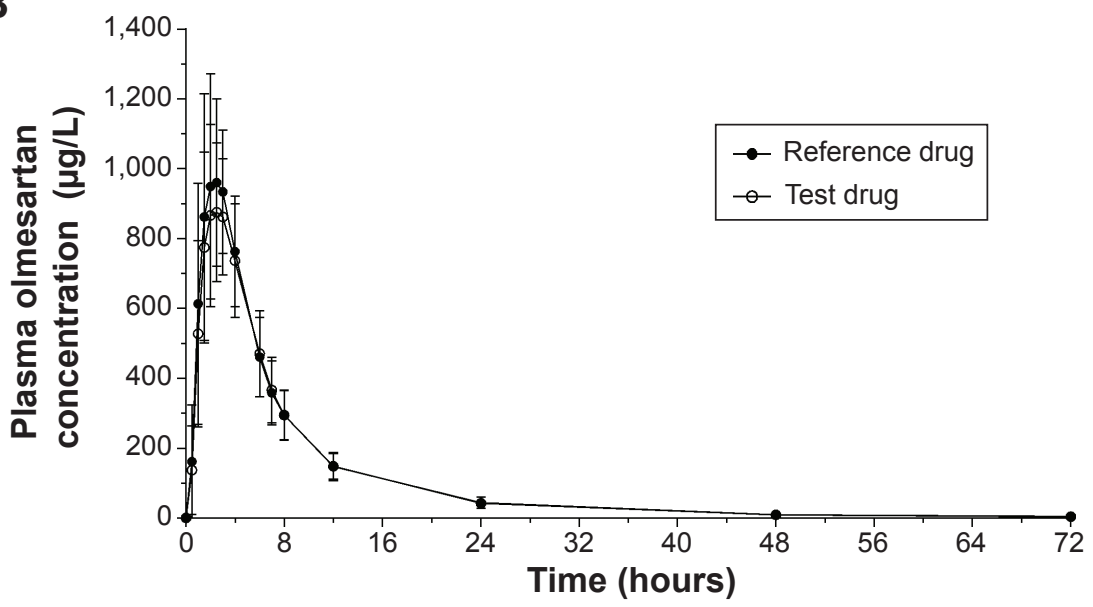

Figure I Mean plasma concentrations of amlodipine (A) and olmesartan (B) after a single oral dose of the test and reference drugs in healthy subjects.

Notes: Error bars represent standard deviation. Test drug, amlodipine orotate/olmesartan medoxomil I0/40 mg (G304I TM); reference drug, amlodipine besylate/olmesartan medoxomil 10/40 mg (Sevikar $\left.{ }^{\circledR}\right)$.

Table I Summary of pharmacokinetic parameters and bioequivalence assessment

\begin{tabular}{|c|c|c|c|c|c|}
\hline \multirow[t]{2}{*}{ Parameter } & \multicolumn{2}{|c|}{ Arithmetic mean (SD) } & \multicolumn{2}{|c|}{$\begin{array}{l}\text { Geometric mean } \\
\text { (coefficient of variation }^{\mathrm{b}} \text { ) }\end{array}$} & \multirow{2}{*}{$\begin{array}{l}\text { Geometric } \\
\text { mean ratio } \\
(90 \% \mathrm{CI})\end{array}$} \\
\hline & Test drug & Reference drug & Test drug & Reference drug & \\
\hline \multicolumn{6}{|l|}{ Amlodipine } \\
\hline $\mathrm{C}_{\max }, \mu g / L$ & $6.7(1.2)$ & $7.1(1.2)$ & $6.6(17.3)$ & $7.0(17.3)$ & $\begin{array}{l}0.9340 \\
(0.8963,0.9732)\end{array}$ \\
\hline $\mathrm{AUC}_{\text {last }}$, hours $\mu \mathrm{g} / \mathrm{L}$ & $230.0(47.8)$ & $245.1(51.5)$ & $225.4(20.8)$ & $239.8(21.0)$ & $\begin{array}{l}0.9403 \\
(0.9052,0.9767)\end{array}$ \\
\hline $\mathrm{AUC}_{\text {inf }}$, hours $\mu \mu g / L$ & $327.9(95.7)$ & $349.9(96.8)$ & $315.3(29.2)$ & $338.2(27.7)$ & - \\
\hline $\mathrm{t}_{\max }$, hours $\mathrm{s}^{\mathrm{a}}$ & $6.0(6.0,7.0)$ & $5.8(6.0,6.8)$ & - & - & - \\
\hline$t_{1 / 2}$, hours & $39.9(8.8)$ & $40.5(8.8)$ & $39.0(22.1)$ & $39.7(21.7)$ & - \\
\hline \multicolumn{6}{|l|}{ Olmesartan } \\
\hline $\mathrm{C}_{\max }, \mu \mathrm{g} / \mathrm{L}$ & 972.0 (195.9) & I,067.5 (2I7.6) & $952.4(20.2)$ & I,046.I (20.4) & $\begin{array}{l}0.9095 \\
(0.8503,0.9730)\end{array}$ \\
\hline $\mathrm{AUC}_{\text {last }}$, hours $\mu \mathrm{gg} / \mathrm{L}$ & $6,976.3(1,365.8)$ & $7,248.6(I, 635.5)$ & 6,839.I (19.6) & $7,065.5(22.6)$ & $\begin{array}{l}0.9668 \\
(0.9241,1.0115)\end{array}$ \\
\hline AUC $_{\text {inf }}$, hours $\mu \mathrm{g} / \mathrm{L}$ & $7,062.6(1,374.2)$ & $7,347.4(I, 650.4)$ & $6,926.9(19.5)$ & $7,065.5(22.5)$ & - \\
\hline $\mathrm{t}_{\max }$, hours $^{\mathrm{a}}$ & $2.3(2.0,2.5)$ & $2.2(1.6,2.5)$ & - & - & - \\
\hline $\mathrm{t}_{1 / 2}$, hours & $10.9(4.2)$ & $11.1(4.1)$ & $10.2(38.9)$ & $10.5(37.0)$ & - \\
\hline
\end{tabular}

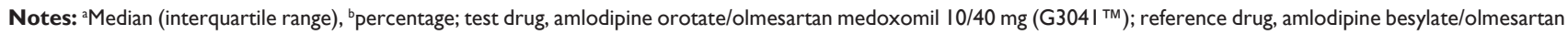
medoxomil 10/40 mg (Sevikar $\left.{ }^{\circledR}\right)$.

Abbreviations: $\mathrm{AUC}_{\text {inf }}$, area under the plasma concentration-time curve from time 0 extrapolated to infinity; $\mathrm{AUC}_{\text {last' }}$, area under the plasma concentration-time curve from time 0 to the last measurable concentration; $\mathrm{Cl}$, confidence interval; SD, standard deviation. 

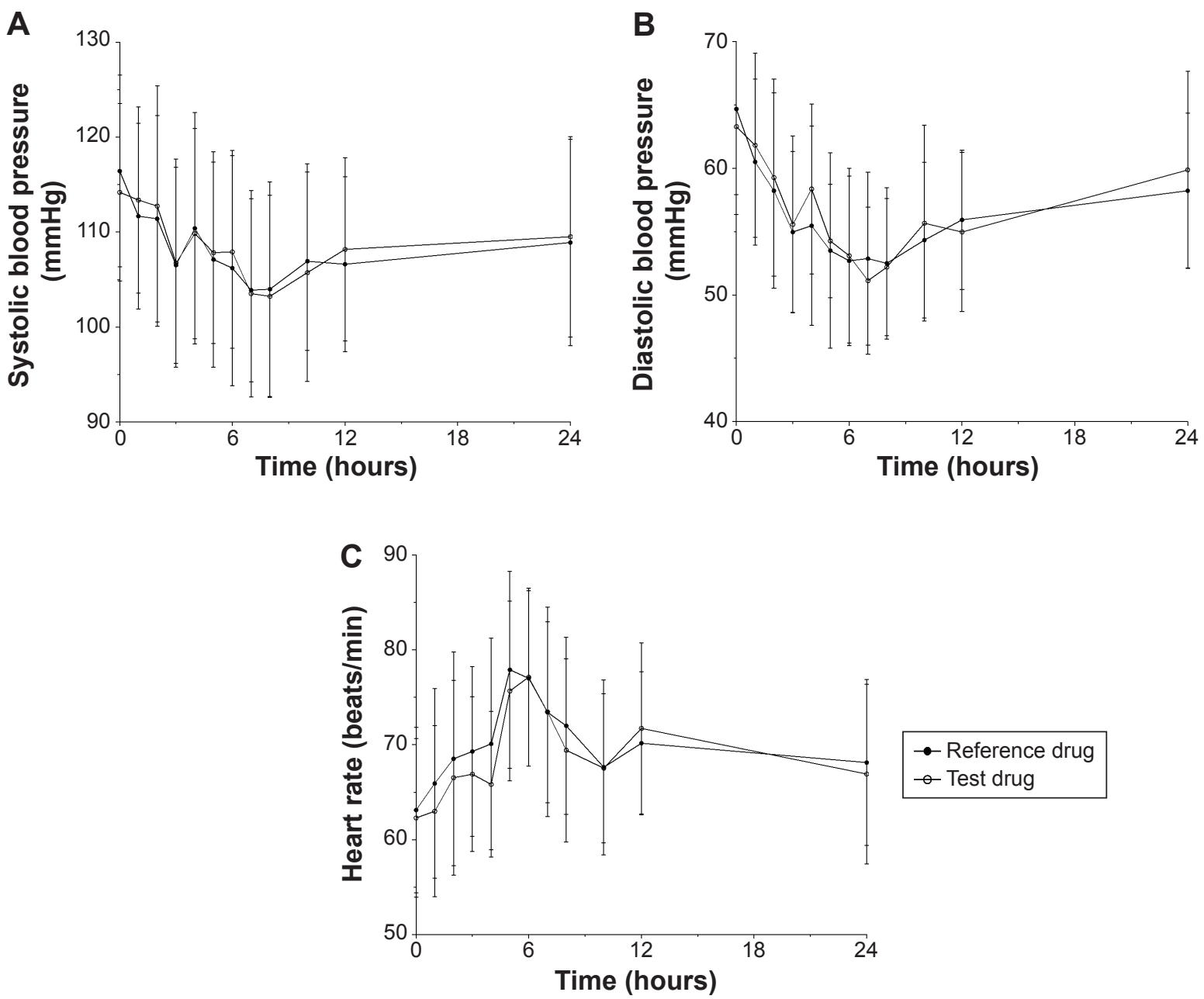

Figure 2 Mean changes in systolic $(\mathbf{A})$ and diastolic $(\mathbf{B})$ blood pressure, and heart rate $(\mathbf{C})$ after a single oral dose of the test and reference drugs in healthy subjects. Notes: Error bars represent standard deviation. Test drug, amlodipine orotate/olmesartan medoxomil I0/40 mg (G304/ TM); reference drug, amlodipine besylate/olmesartan medoxomil 10/40 mg $\left(\right.$ Sevikar $\left.^{\circledR}\right)$.

lower in the present study than in previous studies, whereas olmesartan exposure was slightly higher. ${ }^{6}$ A similar antihypertensive effect was observed between the two study drugs. Both drugs displayed a similar safety profile.

The amlodipine/olmesartan fixed-dose combination effectively reduces blood pressure and attenuates the AEs of the amlodipine component in hypertensive patients. ${ }^{9}$ The combination of amlodipine $10 \mathrm{mg}$ plus olmesartan $40 \mathrm{mg}$ reduced systolic blood pressure by $30.1 \mathrm{mmHg}$, a $53 \%$ greater reduction than that produced with $10 \mathrm{mg}$ amlodipine alone in patients with mild to severe hypertension. Diastolic blood pressure was reduced by $19 \mathrm{mmHg}$, compared with $12.7 \mathrm{mmHg}$ for amlodipine alone. All combinations of amlodipine $10 \mathrm{mg}$ with olmesartan demonstrated less peripheral edema than amlodipine $10 \mathrm{mg}$ monotherapy. ${ }^{9}$

Amlodipine base is not water-soluble and must therefore be manufactured as a salt form. Amlodipine was first marketed as a besylate salt. Although the besylate salt is

Table 2 Summary of pharmacodynamic parameters

\begin{tabular}{|c|c|c|c|c|c|c|}
\hline \multirow[t]{3}{*}{ Parameters } & \multicolumn{6}{|c|}{ Arithmetic mean (SD) } \\
\hline & \multicolumn{2}{|l|}{ Systolic BP } & \multicolumn{2}{|l|}{ Diastolic BP } & \multicolumn{2}{|l|}{ Heart rate } \\
\hline & Test drug & Reference drug & Test drug & Reference drug & Test drug & Reference drug \\
\hline$\triangle$ AUEC $_{24}$, hours $\cdot \mathrm{mmHg}$ & $-\mid 40.5(\mid 48.9)$ & $-209.2(\mid 82.2)$ & $-160.2(101.3)$ & $-203.6(108.9)$ & $167.6(128.8)$ & $162.0(99.9)$ \\
\hline$\Delta \mathrm{E}_{\max }, \mathrm{mmHg}$ & $-12.9(16.6)$ & $-20.0(9.5)$ & $-14.1(7.9)$ & $-17.4(5.3)$ & I8.8 (8.5) & $18.2(5.5)$ \\
\hline$T_{\text {Emax }}$, hours & $7.7(4.1)$ & $7.6(5.2)$ & $7.4(3.6)$ & $7.7(4.9)$ & $7.1(4.0)$ & $6.9(4.9)$ \\
\hline
\end{tabular}

Notes: Test drug, amlodipine orotate/olmesartan medoxomil 10/40 mg (G304I $\left.{ }^{\mathrm{TM}}\right)$; reference drug, amlodipine besylate/olmesartan medoxomil $10 / 40 \mathrm{mg}\left(\right.$ Sevikar $\left.{ }^{\circledR}\right)$. Abbreviations: $\mathrm{AUEC}_{24}$, area under the effect-time curve from time 0 to 24 hours; $\mathrm{E}_{\max }$, maximum effect; $\mathrm{BP}$, blood pressure; SD, standard deviation; $\mathrm{T}_{\mathrm{Emax}}$, time to $\mathrm{E}_{\max }$ 
Table 3 Summary of adverse events

\begin{tabular}{lll}
\hline Adverse event & \multicolumn{2}{l}{$\begin{array}{l}\text { Subjects with adverse events, } \\
\mathbf{n}(\%)\end{array}$} \\
\cline { 2 - 3 } & Test drug & Reference drug \\
\hline Total & $7(23.3)$ & $\mathrm{II}(36.7)$ \\
Sensation of foreign body & $0(0.0)$ & $\mathrm{I}(3.3)$ \\
Tooth abscess & $0(0.0)$ & $\mathrm{I}(3.3)$ \\
Hemoglobin decreased & $\mathrm{I}(3.3)$ & $0(0.0)$ \\
Back pain & $0(0.0)$ & $\mathrm{I}(3.3)$ \\
Headache & $4(13.3)$ & $7(23.3)$ \\
Somnolence & $\mathrm{I}(3.3)$ & $\mathrm{I}(3.3)$ \\
Dysphonia & $0(0.0)$ & $\mathrm{I}(3.3)$ \\
Nasal congestion & $0(0.0)$ & $\mathrm{I}(3.3)$ \\
Rhinorrhea & $\mathrm{I}(3.3)$ & $0(0.0)$ \\
\hline
\end{tabular}

Notes: Test drug, amlodipine orotate/olmesartan medoxomil 10/40 mg (G304 I TM); reference drug, amlodipine besylate/olmesartan medoxomil I0/40 mg (Sevikar ${ }^{\circledR}$ )

highly suitable for the preparation of pharmaceutical formulations of amlodipine, efforts to develop different salt forms of amlodipine have been made for various reasons (eg, to avoid patent protection or to improve the stability of formulations).$^{10}$ Although the maleate salt is the most commonly used salt form after the besylate salt, a number of concerns exist with the maleate salt, including inherent instability. ${ }^{11,12}$ In addition to these tablet manufacturing issues, a concern regarding nephrotoxicity of maleic acid was identified in rodents. ${ }^{13,14}$

Other salt forms have been developed to provide improved physicochemical properties, including high solubility, good stability, non-hygroscopicity, and processibility for tablet formulation. These salts include camsylate, nicotinate, adipate, and orotate, ${ }^{15,16}$ and have been shown not to be different from the besylate salt form in terms of efficacy and tolerability in patients with mild to moderate hypertension. ${ }^{17-20}$ In particular, amlodipine orotate shows enhanced absorption after oral administration in vagotomized dogs, which mimic the low gastric acidity (hypoacidity or anacidity) condition in patients. ${ }^{21}$ Thus, although dogs might be different from humans, amlodipine orotate is likely preferable for patients with low gastric acidity.

Despite the potential advantage of amlodipine orotate, no bioequivalence studies on the combination of amlodipine orotate and olmesartan medoxomil have been published. The present study was therefore conducted to evaluate the bioequivalence of two amlodipine salts, besylate and orotate, each in fixed-dose combination with olmesartan in healthy subjects.

Our results were obtained in conditions that may not be relevant to the practical clinical situation. The characteristics of a homogenous group of healthy study subjects may greatly differ from those of the target patient population, eg, elderly people with several comorbidities who are on polypharmacy for the treatment of hypertension and/or ischemic heart disease, and other vulnerable people, such as women or children, with a risk of reproductive toxicity and fetotoxicity; thus, extrapolation may not be justified. ${ }^{22}$ In addition, considering pharmacogenetic polymorphism, our findings may have been inappropriately extrapolated to other ethnic groups. ${ }^{23-25}$ Collectively, further studies may be needed to justify long-term therapeutic interchangeability in a large population of patients with hypertension.

\section{Conclusion}

In this randomized, open-label study, amlodipine orotate and besylate, each in combination with a fixed dose of olmesartan, were bioequivalent and well tolerated, suggesting that the two fixed-dose combinations investigated could be used interchangeably in clinical practice.

\section{Acknowledgment}

The authors thank the volunteers who took part in this study and the members of the SMC Clinical Trial Center team for their hard work. This study was sponsored and funded by Dong-A ST Co Ltd.

\section{Disclosure}

MYB is an employee of Dong-A ST Co Ltd, Seoul, Republic of Korea. The authors have no other conflicts of interest in this work.

\section{References}

1. Law V, Knox C, Djoumbou Y, et al. DrugBank 4.0: shedding new light on drug metabolism. Nucleic Acids Res. 2014;42(D1):D1091-D1097.

2. Gilman AG, Rall TW, Nies AS, Taylor P. Treatment of Myocardial Ischemia and Hypertension. The Pharmacological Basis of Therapeutics. Oxford, New York: Pergamon Press, 1990.

3. de Gasparo M, Catt K, Inagami T, Wright J, Unger T. International union of pharmacology. XXIII. The angiotensin II receptors. Pharmacol Rev. 2000;52(3):415-472

4. Song J, White C. Olmesartan medoxomil (CS-866) - an angiotensin II receptor blocker for treatment of hypertension. Formulary. 2001;36(7):487-499

5. Mancia G, Fagard R, Narkiewicz K, et al. 2013 ESH/ESC guidelines for the management of arterial hypertension. Eur Heart J. 2013;34: 2159-2219.

6. Rohatagi S, Lee J, Shenouda M, et al. Pharmacokinetics of amlodipine and olmesartan after administration of amlodipine besylate and olmesartan medoxomil in separate dosage forms and as a fixed-dose combination. J Clin Pharmacol. 2008;48(11):1309-1322.

7. Bolbrinker J, Huber M, Scholze J, Kreutz R. Pharmacokinetics and safety of olmesartan medoxomil in combination with either amlodipine or atenolol compared to respective monotherapies in healthy subjects. Fundam Clin Pharmacol. 2009;23(6):767-774. 
8. International Conference on Harmonisation Working Group. ICH harmonised tripartite guideline: guideline for good clinical practice E6 (R1). Available from: http://www.ich.org/fileadmin/Public_Web_Site/ ICH_Products/Guidelines/Efficacy/E6/E6_R1_Guideline.pdf. Accessed May 4, 2015.

9. Pimenta E, Oparil S. Fixed combinations in the management of hypertension: patient perspectives and rationale for development and utility of the olmesartan-amlodipine combination. Vasc Health Risk Manag. 2008;4(3):653.

10. Mignini F, Tomassoni D, Traini E, Amenta F. Single-dose, randomized, crossover bioequivalence study of amlodipine maleate versus amlodipine besylate in healthy volunteers. Clin Exp Hypertens. 2007; 29(8):539-552.

11. Verbeeck R, Kanfer I, Walker R. Generic substitution: the use of medicinal products containing different salts and implications for safety and efficacy. Eur J Pharm Sci. 2006;28(1):1-6.

12. Davison E, Wells JID. Salts of amlodipine. Google Patents; 1990.

13. Harrison HE, Harrison HC. Experimental production of renal glycosuria, phosphaturia, and aminoaciduria by injection of maleic acid. Science. 1954;120(3120):606-608.

14. Angielski S, Rogulski J. Aminoaciduria caused by maleic acid. III. The effect of sulfhydryl compounds. Acta Biochim Pol. 1958;6: 411-415.

15. Park J-Y, Kim K-A, Lee G-S, et al. Randomized, open-label, two-period crossover comparison of the pharmacokinetic and pharmacodynamic properties of two amlodipine formulations in healthy adult male Korean subjects. Clin Ther. 2004;26(5):715-723.

16. Park J, Kim K, Park P, et al. Comparative pharmacokinetic and pharmacodynamic characteristics of amlodipine besylate and amlodipine nicotinate in healthy subjects. Int J Clin Pharmacol Ther. 2006;44(12): 641-647.

17. Kim S-H, Kim Y-D, Lim D-S, et al. Results of a phase III, 8-week, multicenter, prospective, randomized, double-blind, parallel-group clinical trial to assess the effects of amlodipine camsylate versus amlodipine besylate in Korean adults with mild to moderate hypertension. Clin Ther. 2007;29(9):1924-1936.
18. Kim SA, Park S, Chung N, et al. Efficacy and safety profiles of a new S-amlodipine nicotinate formulation versus racemic amlodipine besylate in adult Korean patients with mild to moderate hypertension: an 8-week, multicenter, randomized, double-blind, double-dummy, parallel-group, phase III, noninferiority clinical trial. Clin Ther. 2008;30(5): 845-857.

19. Lee H-Y, Kang H-J, Koo B-K, et al. Clinic blood pressure responses to two amlodipine salt formulations, adipate and besylate, in adult Korean patients with mild to moderate hypertension: a multicenter, randomized, double-blind, parallel-group, 8-week comparison. Clin Ther. 2005;27(6):728-739.

20. Hong SJ, Ahn T-N, Baek S-H, et al. Comparison of efficacy and tolerability of amlodipine orotate versus amlodipine besylate in adult patients with mild to moderate hypertension: a multicenter, randomized, double-blind, placebo-controlled, parallel-group, 8-week follow-up, noninferiority trial. Clin Ther. 2006;28(4):537-551.

21. Kwak HH, Kim JO, Chung HK, et al. Pharmacokinetics of oral amlodipine orotate in vagotomized dogs. Biopharm Drug Dispos. 2006; 27(3):141-145.

22. Meredith P. Bioequivalence and other unresolved issues in generic drug substitution. Clin Ther. 2003;25(11):2875-2890.

23. Kim K-A, Park P-W, Lee O-J, et al. Effect of CYP3A5*3 genotype on the pharmacokinetics and pharmacodynamics of amlodipine in healthy Korean subjects. Clin Pharmacol Ther. 2006;80(6):646-656.

24. Kim K-A, Park P-W, Park J-Y. Effect of ABCB1 (MDR1) haplotypes derived from G2677T/C3435T on the pharmacokinetics of amlodipine in healthy subjects. Br J Clin Pharmacol. 2007;63(1):53-58.

25. Kim CO, Cho SK, Oh ES, Park MS, Chung J-Y. Influence of ABCC2, SLCO1B1, and ABCG2 polymorphisms on the pharmacokinetics of olmesartan. J Cardiovasc Pharmacol. 2012;60(1):49-54.

\section{Publish your work in this journal}

Drug Design, Development and Therapy is an international, peerreviewed open-access journal that spans the spectrum of drug design and development through to clinical applications. Clinical outcomes, patient safety, and programs for the development and effective, safe, and sustained use of medicines are a feature of the journal, which

\section{Dovepress}

has also been accepted for indexing on PubMed Central. The manuscript management system is completely online and includes a very quick and fair peer-review system, which is all easy to use. Visit http://www.dovepress.com/testimonials.php to read real quotes from published authors. 